\title{
Reliability Availability Maintainability Analysis in Forming Industry
}

\author{
Velmurugan K, Venkumar P, Sudhakarapandian R
}

\begin{abstract}
Nowadays the manufacturing industries are facing number of challenges like competitive market environment, dynamic demand, and customer satisfaction. In that situation the Maintenance Management System (MMS) act as one of the most important factors in the manufacturing industries because it directly reflects on the productivity of the industries. The main goal of this research is to analyses the maintenance activity in a Small and Medium sized Enterprise (SME) industry and suggest best maintenance management policy of the given working environment. In this research Markov Analysis is used for predicting future sequence maintenance activity model because the Markov model is powerful tool for Reliability, Maintainability and Safety (RMS) engineering as well as it is simplistic modeling approach for reliability measurement with respect to value of Reliability Availability Maintainability (RAM) of the system for this research analysis we choose these three function because this functions are directly depends on the better MMS. All the mathematical functions are solved by using MATLAB software. The output of the proposed model suggests the new sequence of the maintenance model with optimal cost and categories the maintenance activity then proposed the new check sheet for scheduled maintenance of the given manufacturing environment. This model is suitable for the purpose of achieving high productivity and better customer satisfaction.
\end{abstract}

Keywords: Maintenance Management System, Reliability Availability Maintainability, Markov Model.

\section{INTRODUCTION}

In the recent world the analysis of the Reliability Availability Maintainability (RAM) is act as the major role of all the manufacturing industries so we decide to start analysis studies in the maintenance activity of the industries. For this research and analysis we are choosing forming industry in southern region of Tamilnadu, India. In this (SMEs) industry is produced a lot of child parts to the major automobile manufacturing industry for finished their achievement. This sheet metal forming industry

Revised Manuscript Received on December 5, 2019

* Correspondence Author

Velmurugan K, Research Scholar, Department of Mechanical Engineering, Kalasalingam Academy of Research and Education, Krishnankoil, Tamil Nadu, India. velmurugan@klu.ac.in

Venkumar P*, Professor, Department of Mechanical Engineering, Kalasalingam Academy of Research and Education, Krishnankoil, Tamil Nadu, India. p.venkumar@klu.ac.in

Sudhakarapandian R, Professor, Department of Manufacturing Engineering, Vellore Institute of Technology, Vellore, Tamil Nadu, India. sudhame@gmail.com a Small and Medium sized Enterprise (SME) of the metal

having some of the major manufacturing operations. They are Shearing, Bending, Piercing and joining process. These major operations are used for achieve their production work.

\section{Literature REVIEW}

Aggarwal Vikrant et.al [1] discussed about the Maintenance Management System (MMS) of the paper making system. The condition and availability of critical subsystem is measured by using the Markov Analysis and the output is the implementation of the critical subsystem availability for the paper making system. G.K.Chan and Asgarpoor [2] discussed about the electric power delivery to assist the management and to improve the system availability and reducing operation maintenance cost by applied the Markov Analysis technique to predict the maximum availability of the components and MATLAB software is used for solving the mathematical formulation of the given analysis Mahadevan ML et.al [3] discussed in detail about the Preventive Maintenance Management System of the cement processing industry. In that research they used the non-traditional optimization techniques for predicting the maximum availability of the given manufacturing machine components. . Rachna Chawla and Girish kumar [4] explained in detail about the Condition Based Maintenance Model of the repairable machine components for maximum availability of the given repairable system. They used the Ranga Kutta method to solve the mathematical equation with the help of the MATLAB software and Markov Model also apply for predicting the condition based optimal maintenance policy for the repairable components Seo J.H and Bai D.S [5] discussed in detail about the optimal maintenance policy of the machine components with minimum overhaul period and maintenance function. In this condition they used weibull distribution function to solve the mathematical equation and identify the minimum overhaul period for the given machine components Problem Statement and Solution Technique.Kadiyan et.al [6] detailed discussed about the reliability analysis of the uncaser system of beer manufacturing industry by applied the Markov birth death analysis for predict the performance analysis of the given system. Finally they predict the most critical subsystem of uncaser system of beer manufacturing industry. Nguyen.D and Bagajewicz [7] explained the optimal maintenance systems in processing industry by applied the Monte carlo Simulation techniques for evaluate the expected maintenance cost of various components in industry as well as they identify the expected economic loss and then produced the optimal 
preventive maintenance plan to the process industry. C.Richard Cassady and Erhan Kutanoglu [8] Explained about the optimal maintenance management system given process industry.

They are used the preventive maintenance(PM) analysis and job scheduling problem for predict the better preventive maintenance and optimal scheduling of job in process industry. In this analysis they are applied the weibull distribution function to solving the mathematical problem. Mirabedini S.N and Iranmanesh S.H [9] detailed discussed about the Preventive Maintenance (PM) and Production Scheduling (PS) of the process industry. In this research they are used Multi Objective Genetic Algorithm (MOGA) for predicting the maximum availability and minimum maintenance cost of the given machine components of the process industry.

Nowadays the Manufacturing and Production Industries act as a most important role in the world. They are facing lots of problems in manufacturing process and the one of the main problem is achieve availability of the machine components and periodic maintenance activity of the MMS. It is the key function of all the manufacturing and Production industries because that is directly related to production. For this research a sheet metal industry is selected. They have standard manufacturing process flow as well as some existing maintenance process like they are doing maintenance activity after the systems failed. Only they are doing breakdown maintenance and unplanned preventive maintenance activity of the working environment

\section{A. Problem Statement}

The main problem is unplanned Maintenance Management System in the Sheet Metal Forming industry. In forming industry also having the existing methods of maintenance process but they are spending more money and time for making the maximum availability of the critical subsystem in manufacturing process. That is directly affecting the total productivity of the Forming industry. In that condition we are focusing the most important and critical child part manufacturing process. That is Fuel Tank Mounding part manufacturing process and the machine. Because this part and manufacturing process is more important than the other part manufacturing process of the sheet metal forming industry.

First we monitor the existing manufacturing process and Maintenance activity of the Fuel Tank Mounding part operation and discuss with plant employee for select the most critical operation process in the following flow process then we discuss with the maintenance people for classifying the critical subsystem in that particular manufacturing operation machine for the further investigation of our research studies in the Sheet Metal Forming industry.

\section{B. Markov Analysis}

The Markov Analysis is the one of the best analysis techniques for the RAM and MMS to predict the new sequence of the maintenance model with respect to the present behavior of the variables. The RAM of the critical subsystem can be founded using the familiar Markov
Analysis. In this analysis technique we assumed to a failure and repair rate of the critical subsystem is constant. In that condition we consider the three stages of the critical subsystems that's good stage, degrade stage and failed stage. In the RAM analysis of the critical subsystem $\mathrm{O}$ is denoted as the original or good condition of the critical subsystem $\mathrm{R}$ denoted as the repair of the critical subsystem and $M$ denoted a under the maintenance of the critical subsystem. When using Markov the random variable is indexed in time, which can be either discrete or continuous.

This Markov Model is classified into two types. They are

\section{Markov Chain (Discrete) \\ 2. Markov Analysis (Continuous)}

\section{Manufacturing Model}

We choose the Small and Medium sized Enterprise of Sheet Metal Forming industry in southern region of Tamilnadu, India. In sheet metal forming industry the Fuel Tank Mounding part manufacturing process is one of the most critical processes because that part having the some difficult profile shape and bending operation for achieving the customer satisfaction. In the sheet metal forming industry reach the maximum profit by producing more number of Fuel Tank Mounding Part to the automobile vehicle manufacturing industry. In this process the raw material (Sheet Metal) is converted into a finished part (Fuel Tank Mounding part) and the sequence operation of the manufacturing process is shown in Fig. 1.

\section{Analysis AND Mathematical Model}

In this research study to analyze detailed maintenance function in Fuel Tank Mounding part manufacturing process in sheet metal forming industry and apply Markov analysis techniques are used to produce the optimal maintenance schedule for the maintenance department.

First we analyzed the Fuel Tank Mounding part manufacturing process in detail then identify the most critical or important operation of the given manufacturing process of the sheet metal forming industry then we select that particular machine for further analysis of this research study. After that we discuss with maintenance department for identifying the most critical subsystems of that machine. Finally we monitor the manufacturing activity of that machine and collect the data of failure and repair rate of the critical subsystems of that particular machine in forming industry.

In this research study we are applied the Markov Analysis for the maintenance management activity to solve the maintenance problem because this analysis technique is most widely used for identify the availability of the systems and predict the optimal maintenance model of the given working environment. This analysis technique helps to predict the maximum RAM of the given critical subsystem and rearrange the preventive maintenance sequence with respect to the value of the repair and failure rate of the given critical subsystem and then produce the future sequence of the maintenance model to achieve the optimal maintenance model 


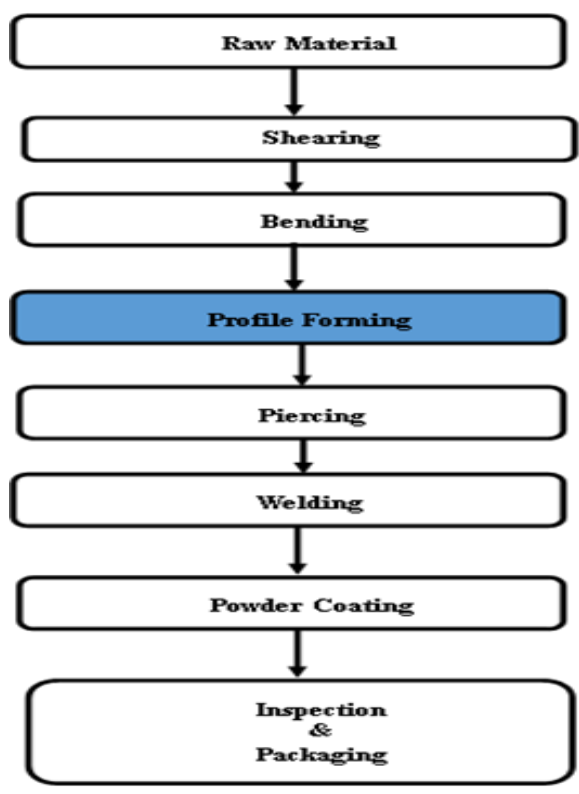

Fig. 1.Manufacturing Process

\section{A. Maintenance Model}

In Fuel Tank Mounding part manufacturing process the main and major operation is to select and apply the analysis techniques. We selected the Profile Forming operation. For that operation they are used the 500 Ton Hydraulic Pressing machine to achieve the required shape of the given sheet metal in forming industry. In this profile forming machine having some important sub critical subsystems like Hydraulic Pump, Actuators, Control and Relief valve. The classification of the critical subsystems are shown in Fig.2

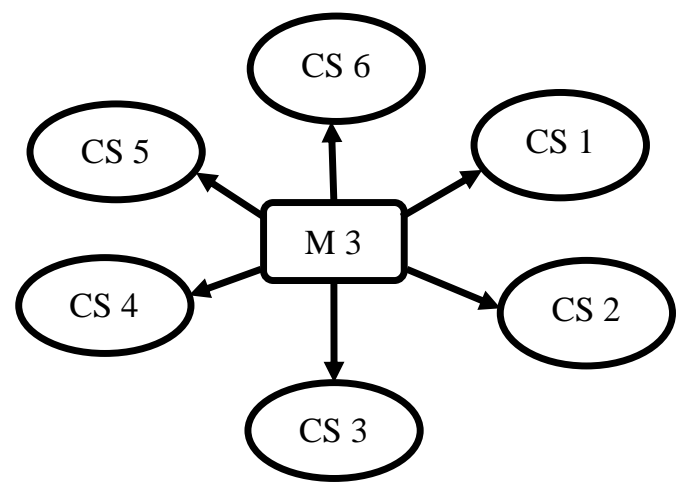

Fig. 2.critical subsystem

\section{B. Sample Process}

In this section explain in detail about the transition state diagram of the critical subsystems from original state to maintenance and repair state then back to the original state of the manufacturing machine. From this transition diagram we generate the formulation of the given analysis technique (Markov Analysis) for measure the availability of the given critical subsystems of manufacturing machine in forming industry. The sample operation and mathematical function of the single subcritical system is shown in Fig.3

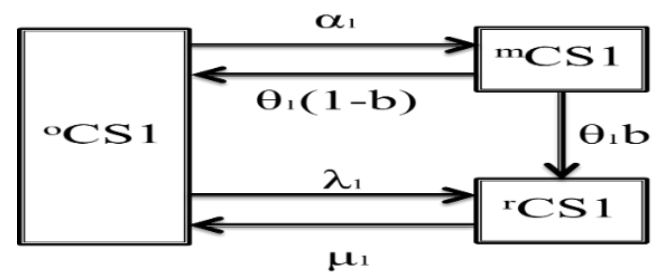

Fig. 3.Sample Process

\section{Notation and Symbols}

The following symbols and notations are used for solving the Markov Analysis.

"oCS" the Critical System is original.

"rCS" is under repair condition.

"mCS" under maintenance condition.

" $\lambda$ " refer respective failure rate the CS.

" $\mu$ " refer respective repair rate the CS.

" $\alpha$ " Constant transition rate of the CS.

" $\theta$ " refer the respective PM rate of CS.

"CS" refer the Critical Subsystem.

P0 (t) refer the probability function of all critical subsystems are original condition.

$\mathrm{P} 1(\mathrm{t})$ refer the probability function of critical subsystem 1 is reduced life under the maintenance condition.

$\mathrm{P} 2(\mathrm{t})$ refer the probability function of critical subsystem 1 is under the repair state.

P3(t) refer the probability function of critical subsystem 2 is reduced life under the maintenance condition.

$\mathrm{P} 4(\mathrm{t})$ refer the probability function of critical subsystem 2 is under the repair state.

$\mathrm{P} 5(\mathrm{t})$ refer the probability function of critical subsystem 3 is reduced life under the maintenance condition.

P6(t) refer the probability function of critical subsystem 3 is under the repair state.

P7(t) refer the probability function of critical subsystem 4 is reduced life under the maintenance condition.

P8(t) refer the probability function of critical subsystem 4 is under the repair state.

$\mathrm{P} 9(\mathrm{t})$ refer the probability function of critical subsystem 5 is reduced life under the maintenance condition.

$\mathrm{P} 10(\mathrm{t})$ refer the probability function of critical subsystem 5 is under the repair state.

P11(t) refer the probability function of critical subsystem 6 is reduced life under the maintenance condition.

$\mathrm{P} 12(\mathrm{t})$ refer the probability function of critical subsystem 6 is under the repair state.

\section{Assumptions}

The various assumptions considered in this proposed model are as follows:-

i. All the subsystems are initially operating and are in good state.

ii. Every subsystem has three states viz. good, degraded and failed.

iii. Every subsystem is as original as new after repair.

iv Failure and repair events are statistically independent. 


\section{Reliability Availability Maintainability Analysis in Forming Industry}

$\mathrm{v}$ The failure, repair and preventive maintenance rates are consider as constant.

\section{E. Formulation of the System}

For predict the RAM of the critical subsystem in Sheet Metal Forming industry the theoretical formulation of the given maintenance model is solved by using the first order differential equation with the help of the transition diagram as shown in Fig.3.we develop the Markov analysis of critical subsystem in three state viz. original, maintenance and repair

The probability function of the CS 1 transition from the original state to repair state of mathematical equation is given below

$$
P_{1}(t)+\theta_{1} P_{1}(t)=\alpha_{1} P_{0}(t)
$$

The probability function of the CS 1 transition from the repair state to maintenance state and then back to the original state of mathematical equation is given below

$$
P_{2}(t)+\mu_{1} P_{2}(t)=\theta_{1} b P_{1}(t)+\lambda_{1} P_{0}(t)
$$

The probability function of the CS 2 transition from the original state to repair state of mathematical equation is given below

$$
P_{3}(t)+\theta_{2} P_{3}(t)=\alpha_{2} P_{0}(t)
$$

The probability function of the CS 2 transition from the repair state to maintenance state and then back to the original state of mathematical equation is given below

$$
P_{4}(t)+\mu_{2} P_{4}(t)=\theta_{2} b P_{3}(t)+\lambda_{2} P_{0}(t)
$$

The probability function of the CS 3 transition from the original state to repair state of mathematical equation is given below

$$
P_{5}(t)+\theta_{3} P_{5}(t)=\alpha_{3} P_{0}(t)
$$

The probability function of the CS 3 transition from the repair state to maintenance state and then back to the original state of mathematical equation is given below

$$
P_{6}(t)+\mu_{3} P_{6}(t)=\theta_{3} b P_{5}(t)+\lambda_{3} P_{0}(t)
$$

The probability function of the CS 4 transition from the original state to repair state of mathematical equation is given below

$$
P_{7}(t)+\theta_{4} P_{7}(t)=\alpha_{4} P_{0}(t)
$$

The probability function of the CS 4 transition from the repair state to maintenance state and then back to the original state of mathematical equation is given below

$$
P_{8}(t)+\mu_{4} P_{8}(t)=\theta_{4} b P_{7}(t)+\lambda_{4} P_{0}(t)
$$

The probability function of the CS 5 transition from the original state to repair state of mathematical equation is given below

$$
P_{9}(t)+\theta_{5} P_{9}(t)=\alpha_{5} P_{0}(t)
$$

The probability function of the CS 5 transition from the repair state to maintenance state and then back to the original state of mathematical equation is given below

$$
P_{10}(t)+\mu_{5} P_{10}(t)=\theta_{5} b P_{9}(t)+\lambda_{5} P_{0}(t)
$$

The probability function of the CS 6 transition from the original state to repair state of mathematical equation is given below

$$
P_{11}(t)+\theta_{6} P_{11}(t)=\alpha_{6} P_{0}(t)
$$

The probability function of the CS 6 transition from the repair state to maintenance state and then back to the original state of mathematical equation is given below

$$
P_{12}(t)+\mu_{6} P_{12}(t)=\theta_{6} b P_{11}(t)+\lambda_{6} P_{0}(t)
$$

The steady state availability of the given critical subsystems apply the $\mathrm{t}=0$ at the equation 1-12 then the steady state probability function is given below

$$
\begin{aligned}
& \theta_{1} P_{1}=\alpha_{1} P_{0} \\
& \mu_{1} P_{2}=\theta_{1} b P_{1}+\lambda_{1} P_{0} \\
& \theta_{2} P_{3}=\alpha_{2} P_{0} \\
& \mu_{2} P_{4}=\theta_{2} b P_{3}+\lambda_{2} P_{0} \\
& \theta_{3} P_{5}=\alpha_{3} P_{0} \\
& \mu_{3} P_{6}=\theta_{3} b P_{5}+\lambda_{3} P_{0} \\
& \theta_{4} P_{7}=\alpha_{4} P_{0} \\
& \mu_{4} P_{8}=\theta_{4} b P_{7}+\lambda_{4} P_{0} \\
& \theta_{5} P_{9}=\alpha_{5} P_{0} \\
& \mu_{5} P_{10}=\theta_{5} b P_{9}+\lambda_{5} P_{0} \\
& \theta_{6} P_{11}=\alpha_{6} P_{0} \\
& \mu_{6} P_{12}=\theta_{6} b P_{11}+\lambda_{6} P_{0}
\end{aligned}
$$

\begin{tabular}{|c|c|c|c|c|c|c|c|}
\hline \multicolumn{2}{|c|}{$\begin{array}{l}\text { Failure Rate } \\
\lambda\end{array}$} & \multicolumn{2}{|c|}{$\begin{array}{l}\text { Repair Rate } \\
\mu\end{array}$} & \multicolumn{2}{|c|}{$\begin{array}{l}\text { Transition } \\
\text { Rate } \alpha\end{array}$} & \multicolumn{2}{|c|}{$\begin{array}{l}\text { Preventive } \\
\text { Maintenance } \\
\text { Rate } \theta\end{array}$} \\
\hline$\lambda_{1}$ & 0.009 & $\mu_{1}$ & 0.55 & $\alpha_{1}$ & 0.004 & $\theta_{1}$ & 0.50 \\
\hline$\lambda_{2}$ & 0.009 & $\mu_{2}$ & 0.51 & $\alpha_{2}$ & 0.006 & $\theta_{2}$ & 0.43 \\
\hline$\lambda_{3}$ & 0.008 & $\mu_{3}$ & 0.6 & $\alpha_{3}$ & 0.004 & $\theta_{3}$ & 0.55 \\
\hline$\lambda_{4}$ & 0.01 & $\mu_{4}$ & 0.5 & $\alpha_{4}$ & 0.005 & $\theta_{4}$ & 0.53 \\
\hline$\lambda_{5}$ & 0.008 & $\mu_{5}$ & 0.6 & $\alpha_{5}$ & 0.006 & $\theta_{5}$ & 0.52 \\
\hline$\lambda_{6}$ & 0.012 & $\mu_{6}$ & 0.58 & $\alpha_{6}$ & & & 0.48 \\
\hline
\end{tabular}

The probability of the critical subsystems original state, maintenance state and repair state identified by using normalizing condition i.e. Total sum of all original, maintenance and repair state probability function is equal to 1.

Using Normalizing condition

$$
\sum_{i=1}^{12} P_{i}=1
$$

$P_{0}=\left(1+\sum_{i=1}^{12} P_{i}\right)^{-1}$

$A_{0}=P_{0}$

Table- I: Numerical values of the Critical subsystem 
The failure and repair rate numerical values of the critical subsystems are shown in Table I. These data are applied to the above mathematical equations and measure the availability of the given critical subsystem with the help of using MATLAB software and the solution of the critical subsystem are shown in Table VI and VII.

After complete the mathematical function the Markov Analysis Technique the availability of the critical subsystems in faulty and repair condition are as shown in the Table II.

Table- II: Availability of the Critical subsystem

\begin{tabular}{|c|c|c|c|c|c|c|}
\hline & CS 1 & CS 2 & CS 3 & CS 4 & CS 5 & CS 6 \\
\hline ठี & $\mathrm{Av}$ & $\mathrm{Av}$ & $\mathrm{Av}$ & $\mathrm{Av}$ & $\mathrm{Av}$ & $\mathrm{Av}$ \\
\hline III & 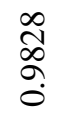 & $\begin{array}{l}\hat{\sigma} \\
\infty \\
\vdots \\
0\end{array}$ & $\begin{array}{l}\infty \\
\curvearrowleft \\
\infty \\
0 \\
0\end{array}$ & $\begin{array}{l}0 \\
\infty \\
0 \\
0\end{array}$ & $\begin{array}{l}\infty \\
\curvearrowleft \\
\infty \\
0 \\
0\end{array}$ & $\begin{array}{l}\tilde{\infty} \\
\infty \\
0 \\
0\end{array}$ \\
\hline لـ & $\frac{\mathfrak{g}}{\frac{2}{a}}$ & $\begin{array}{l}\text { Ð } \\
\stackrel{\sigma}{0}\end{array}$ & $\begin{array}{l}\bar{\rho} \\
\vdots \\
0\end{array}$ & $\frac{\grave{N}}{\hat{a}}$ & 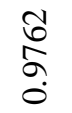 & $\frac{ \pm}{\grave{\sigma}}$ \\
\hline
\end{tabular}

Then rearrange the critical subsystem sequence of the maintenance activity with respect to the maximum availability of the given critical subsystem under the repair condition of the Fuel Tank Mounding Part manufacturing machine in the Sheet Metal Forming Industry the rearrangement of the critical subsystem is shown in Table III

Table- III: Rearrange the critical subsystem in fault condition

\begin{tabular}{|c|c|c|c|c|c|c|}
\hline \multirow{2}{*}{ 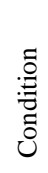 } & CS 3 & CS 5 & CS 1 & CS 4 & CS 6 & CS 2 \\
\hline & $\mathrm{Av}$ & $\mathrm{Av}$ & $\mathrm{Av}$ & $\mathrm{Av}$ & $\mathrm{Av}$ & $\mathrm{Av}$ \\
\hline II & $\begin{array}{l}\overline{2} \\
\vdots \\
0\end{array}$ & $\begin{array}{l}\text { ô } \\
\text { o. } \\
0\end{array}$ & $\begin{array}{l}\hat{a} \\
\hat{o}\end{array}$ & $\frac{\hat{N}}{\hat{o}}$ & $\frac{\mathbb{a}}{\hat{\sigma}}$ & $\begin{array}{l}\text { t } \\
\text { م. } \\
0\end{array}$ \\
\hline
\end{tabular}

The Table IV shows the existing check sheet of the maintenance department in Fuel Tank Mounding Part manufacturing plant of the Sheet Metal Forming Industry

\section{RESULT ANALYSIS}

In the Fuel Tank Mounding Part manufacturing process are successfully carried out the RAM analysis studies in the maintenance department of forming industry. From this research and analysis studies we produce the best and optimal maintenance management policy of the given (SMEs) forming industry. The effective result of this research study is maximize RAM and Reuse full life (RUL) of the critical subsystems in profile forming manufacturing machine in the

forming industry. From this Markov analysis we found the effective rate of failure and repair to achieve the maximum availability of the critical subsystem. The identified value of failure rate is 0.009 and the repair rate is 1.08 this value leads to the maximum availability of the critical subsystem 3 . The RUL of the critical subsystem is identified with respect to variation of the failure rate and repair rate of the given manufacturing machine critical components

Table- IV: Existing check sheet EXISTING CHECK SHEET

PREVENTIVE MAINTENANCE CHECK SHEET

Customer Name:

Unit \#:___PM: ____ Last PM:

Mechanic: _______ate: ____ Next PM Due On:

\begin{tabular}{|l|c|l|l|l|}
\hline $\begin{array}{c}\text { Tasks to be } \\
\text { performed }\end{array}$ & $\begin{array}{l}\text { Inspected } \\
\text { Okay }\end{array}$ & $\begin{array}{l}\text { Repaired \& } \\
\text { Adjusted }\end{array}$ & Replaced & $\begin{array}{l}\text { Comments \& } \\
\text { Parts List }\end{array}$ \\
\hline $\begin{array}{l}\text { Critical } \\
\text { Subsystem 1 }\end{array}$ & $\checkmark$ & & & \\
\hline $\begin{array}{l}\text { Critical } \\
\text { Subsystem 2 }\end{array}$ & $\checkmark$ & & & \\
\hline $\begin{array}{l}\text { Critical } \\
\text { Subsystem 3 }\end{array}$ & & $\checkmark$ & & \\
\hline $\begin{array}{l}\text { Critical } \\
\text { Subsystem 4 }\end{array}$ & $\checkmark$ & & $\checkmark$ & \\
\hline $\begin{array}{l}\text { Critical } \\
\text { Subsystem 5 }\end{array}$ & $\checkmark$ & & & \\
\hline $\begin{array}{l}\text { Critical } \\
\text { Subsystem 6 }\end{array}$ & & $\checkmark$ & & \\
\hline
\end{tabular}

Table- V: Propose check sheet

PROPOSED CHECK SHEET

PREVENTIVE MAINTENANCE CHECK SHEET

Customer Name:

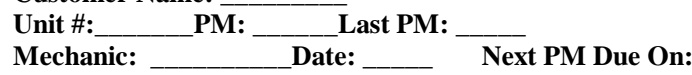

\begin{tabular}{|c|c|c|c|c|c|}
\hline \multicolumn{2}{|c|}{$\begin{array}{l}\text { Task to be } \\
\text { performed }\end{array}$} & $\begin{array}{l}\text { Inspected } \\
\text { Okay }\end{array}$ & $\begin{array}{l}\text { Repaired } \\
\& \\
\text { Adjusted }\end{array}$ & Replaced & $\begin{array}{l}\text { Comments } \\
\& \\
\text { Parts List }\end{array}$ \\
\hline \multicolumn{6}{|c|}{ 4.Profile forming Machine } \\
\hline \multirow{4}{*}{ 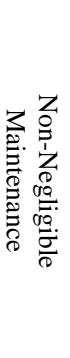 } & $\begin{array}{l}\text { Critical } \\
\text { Subsystem } 3\end{array}$ & $\checkmark$ & & & \\
\hline & $\begin{array}{l}\text { Critical } \\
\text { Subsystem } 5\end{array}$ & $\checkmark$ & & & \\
\hline & $\begin{array}{l}\text { Critical } \\
\text { Subsystem } 1\end{array}$ & $\checkmark$ & & & \\
\hline & $\begin{array}{l}\text { Critical } \\
\text { Subsystem } 4\end{array}$ & $\checkmark$ & & & \\
\hline \multirow{2}{*}{ 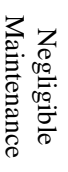 } & $\begin{array}{l}\text { Critical } \\
\text { Subsystem } 6\end{array}$ & $\checkmark$ & & & \\
\hline & $\begin{array}{l}\text { Critical } \\
\text { Subsystem } 2\end{array}$ & & $\checkmark$ & & \\
\hline
\end{tabular}

Published By: 

Table - VI: MATLAB Solutions for repair condition

\begin{tabular}{|c|c|c|c|c|c|c|c|c|c|c|c|c|c|}
\hline \multirow{3}{*}{$\begin{array}{l}\mathrm{B}=1 \\
\text { Sample size }\end{array}$} & \multirow{3}{*}{ 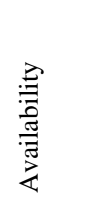 } & \multicolumn{3}{|c|}{ Failure rate $(\lambda)$} & \multicolumn{3}{|c|}{ Repair rate $(\mu)$} & \multicolumn{3}{|c|}{ Transition rate $(\boldsymbol{\alpha})$} & \multicolumn{3}{|c|}{$\begin{array}{l}\text { Preventive Maintenance rate } \\
(\theta)\end{array}$} \\
\hline & & 0.049 & 0.048 & 0.05 & 1.55 & 1.51 & 1.6 & 0.044 & 0.046 & 0.045 & 1.5 & 1.43 & 1.55 \\
\hline & & 0.009 & 0.008 & 0.01 & 0.55 & 0.51 & 0.6 & 0.004 & 0.006 & 0.005 & 0.5 & 0.43 & 0.55 \\
\hline 10 & 0.6447 & 0.010 & 0.009 & 0.031 & 1.08 & 0.90 & 1.27 & 0.019 & 0.041 & 0.014 & 0.69 & 0.85 & 0.56 \\
\hline 20 & 0.6927 & 0.017 & 0.047 & 0.027 & 1.45 & 1.04 & 1.41 & 0.039 & 0.032 & 0.024 & 1.26 & 0.46 & 1.17 \\
\hline 30 & 0.6496 & 0.026 & 0.022 & 0.041 & 1.52 & 1.23 & 0.74 & 0.031 & 0.007 & 0.023 & 1.21 & 0.45 & 1.12 \\
\hline 40 & 0.6551 & 0.037 & 0.026 & 0.019 & 0.58 & 1.01 & 1.52 & 0.015 & 0.013 & 0.025 & 0.97 & 0.84 & 1.32 \\
\hline 50 & 0.6875 & 0.042 & 0.032 & 0.031 & 1.45 & 1.08 & 0.93 & 0.014 & 0.038 & 0.007 & 1.32 & 0.88 & 0.93 \\
\hline 60 & 0.6424 & 0.031 & 0.036 & 0.022 & 0.77 & 1.23 & 1.31 & 0.022 & 0.043 & $0 / 017$ & 0.99 & 1.36 & 1.44 \\
\hline 70 & 0.6995 & 0.047 & 0.030 & 0.009 & 1.01 & 1.00 & 1.08 & 0.005 & 0.023 & 0.029 & 1.08 & 0.71 & 1.37 \\
\hline 80 & 0.6685 & 0.013 & 0.022 & 0.034 & 1.29 & 1.47 & 1.57 & 0.005 & 0.027 & 0.033 & 1.27 & 1.23 & 0.67 \\
\hline 90 & 0.6548 & 0.013 & 0.034 & 0.021 & 0.88 & 1.17 & 0.84 & 0.007 & 0.016 & 0.017 & 1.36 & 0.91 & 0.94 \\
\hline 100 & 0.5956 & 0.031 & 0.010 & 0.014 & 0.67 & 1.04 & 1.50 & 0.030 & 0.043 & 0.012 & 1.35 & 1.00 & 0.86 \\
\hline
\end{tabular}

Table- VII: MATLAB Solution for ideal condition

\begin{tabular}{|c|c|c|c|c|c|c|c|c|c|c|c|c|c|}
\hline \multirow{3}{*}{$\begin{array}{l}\mathrm{B}=0 \\
\text { Sample size }\end{array}$} & \multirow{3}{*}{ 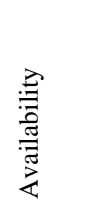 } & \multicolumn{3}{|c|}{ Failure rate $(\lambda)$} & \multicolumn{3}{|c|}{ Repair rate $(\mu)$} & \multicolumn{3}{|c|}{ Transition rate $(\boldsymbol{\alpha})$} & \multicolumn{3}{|c|}{$\begin{array}{l}\text { Preventive Maintenance rate } \\
(\theta)\end{array}$} \\
\hline & & 0.049 & 0.048 & 0.05 & 1.55 & 1.51 & 1.6 & 0.044 & 0.046 & 0.045 & 1.5 & 1.43 & 1.55 \\
\hline & & 0.009 & 0.008 & 0.01 & 0.55 & 0.51 & 0.6 & 0.004 & 0.006 & 0.005 & 0.5 & 0.43 & 0.55 \\
\hline 10 & 0.7253 & 0.010 & 0.009 & 0.031 & 1.08 & 0.90 & 1.27 & 0.019 & 0.041 & 0.014 & 0.69 & 0.85 & 0.56 \\
\hline 20 & 0.7484 & 0.017 & 0.047 & 0.027 & 1.45 & 1.04 & 1.41 & 0.039 & 0.032 & 0.024 & 1.26 & 0.46 & 1.17 \\
\hline 30 & 0.7164 & 0.026 & 0.022 & 0.041 & 1.52 & 1.23 & 0.74 & 0.031 & 0.007 & 0.023 & 1.21 & 0.45 & 1.12 \\
\hline 40 & 0.7325 & 0.037 & 0.026 & 0.019 & 0.58 & 1.01 & 1.52 & 0.015 & 0.013 & 0.025 & 0.97 & 0.84 & 1.32 \\
\hline 50 & 0.7592 & 0.042 & 0.032 & 0.031 & 1.45 & 1.08 & 0.93 & 0.014 & 0.038 & 0.007 & 1.32 & 0.88 & 0.93 \\
\hline 60 & 0.7259 & 0.031 & 0.036 & 0.022 & 0.77 & 1.23 & 1.31 & 0.022 & 0.043 & $0 / 017$ & 0.99 & 1.36 & 1.44 \\
\hline 70 & 0.7527 & 0.047 & 0.030 & 0.009 & 1.01 & 1.00 & 1.08 & 0.005 & 0.023 & 0.029 & 1.08 & 0.71 & 1.37 \\
\hline 80 & 0.7428 & 0.013 & 0.022 & 0.034 & 1.29 & 1.47 & 1.57 & 0.005 & 0.027 & 0.033 & 1.27 & 1.23 & 0.67 \\
\hline 90 & 0.7398 & 0.013 & 0.034 & 0.021 & 0.88 & 1.17 & 0.84 & 0.007 & 0.016 & 0.017 & 1.36 & 0.91 & 0.94 \\
\hline 100 & 0.6706 & 0.031 & 0.010 & 0.014 & 0.67 & 1.04 & 1.50 & 0.030 & 0.043 & 0.012 & 1.35 & 1.00 & 0.86 \\
\hline
\end{tabular}


Finally the critical subsystem of the Fuel Tank Mounding Part manufacturing Machines are classified in two categories with respect to the maximum availability of the given critical subsystem and rearrange the critical subsystem and then proposed the new model check sheet for the better maintenance management system. The proposed check sheet is shown in Table IV.

\section{Conclusion}

From this research study predict the most critical subsystem of the Fuel Tank mounding part manufacturing machine and that critical subsystems are classified in to Negligible / Non negligible maintenance activity with respect to the variation of failure rate, repair rate and maximum availability of the critical subsystem. Suggest the best and optimal maintenance policy to the given sheet metal forming industry by produced the new check sheet and sequence of the planned maintenance model for the better implementation of the MMS in given critical subsystem of the working environment. In future this RAM analysis can be applied using some Nontraditional optimization techniques for predicting the optimal maintenance cost policy with respect to the cost variation of the maintenance activity in the next revolution of the industry.

\section{ACKNOWLEDGMENT}

The authors wish to thank the Management of Kalasalingam Academy of Research and Education [KARE] Krishnankoil, Tamilnadu, India and Vellore Institute of Technology [VIT Vellore, Tamilnadu, India for their support in this research.

\section{REFERENCES}

1. Aggarwal Vikrant, Goyal Atul, "Optimization of paper making system Using Genetic Algorithm," Indian Journal of science and Technology, Vol9 (17)2016.

2. G. K. Chan, and S. Asgarpoor, "Optimum maintenance policy with Markov processes," Electric power systems research, 76(6-7), pp.452-456, 2006.

3. M. L. Mahadeva, S. Poorana Kumar, R. vinoth, T. paul Robert, "Preventive Maintenance Optimization of Critical Equipment in Process Plant Using Heuristic Algorithms," International Conference on industrial Engineering and Operation Management Dhaka. Bangladesh January 9-10,2010.

4. R. Chawla, and G. Kumar, "Condition based maintenance modeling for availability analysis of a repairable mechanical system,".Int J Innov Eng Technol, 2(2), pp.371-379, 2013.

5. J. H. Seo, and D. S. Bai, "An optimal maintenance policy for a system under periodic overhaul," Mathematical and Computer Modelling, 39(4-5), pp.373-380, 2004.

6. S. Kadiyan, R. K. Garg, \& R. Gautam, "Reliability and availability analysis of uncaser system in a brewery plant," Int J Res Mech Eng Technol, 2(2), 7-11, 2012.

7. D. Nguyen, and M. Bagajewicz, "Optimization of preventive maintenance scheduling in processing plants," In Computer Aided Chemical Engineering (Vol. 25, pp. 319-324), 2008 Elsevier.

8. C. R. Cassady, and E. Kutanoglu, "Integrating preventive maintenance planning and production scheduling for a single machine," IEEE Transactions on reliability, 54(2), pp.304-309, 2005.

9. S. N. Mirabedini, H. Mina, and S. H. Iranmanesh, "Multi-objective optimization research on multi parallel machine with different preventive maintenance planning and scheduling with genetic algorithm," International Journal of Academic Research in Business and Social Sciences, 2(12), p.129, 2012.

\section{AUTHORS PROFILE}

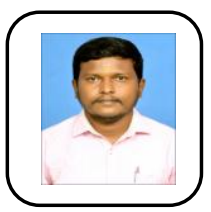

Mr. K. Velmurugan, is currently a Research Scholar, Department of the Mechanical Engineering, in Kalasalingam Academy of Research and Education, Krishnankovil, Tamil Nadu, India. He received his B.E. and M.E., degree in Anna University, Chennai, Tamil Nadu, India, in 2014 and 2017 respectively and pursuing $\mathrm{Ph} . \mathrm{D}$. degree in Kalasalingam Academy of Research and Education, Tamil Nadu, India. His main area of the research interest are Predictive Maintenance Management, Manufacturing system optimization and Smart Maintenance Management.

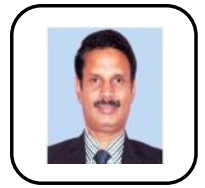

Dr. P. Venkumar, is currently a Senior Professor in Department of Mechanical Engineering, Kalasalingam Academy of Research and Education, Krishnankovil, Tamilnadu, Inida. He received his B.E., and M.E., degrees in Thigagrajar College of Engineering, Madurai, Tamilnadu, India, in 1994 and 1997, respectively and Ph.D. degree in Manonmaniam Sundaranar University, India in Industrial Engineering in 2006. His main areas of research interest are Manufacturing system optimization, Supply chain management and Smart manufacturing.

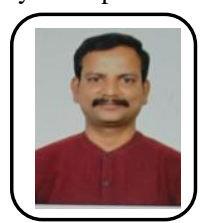

Dr. R. SudhakaraPandian, is currently a Professor in the Department of Manufacturing Engineering, School of Mechanical Engineering at Vellore Institute of Technology, Vellore, Tamil Nadu, India. He has published around 30 International papers in Journals. He is a scientific coordinator of the European Funded H2020 SME 4.0 Project along with Technical University of Kosice, Slovak Republic. He was awarded with Young Engineers Award during 2010 for his contribution in production Engineering by IE (India). His area of research include Lean Manufacturing, Mass Customization, Operations Research and Supply Chain. 